\title{
The 'MeBox' method and the emotional effects of chronic illness on travel
}

\begin{abstract}
Within tourism studies, there has been a gap in attempting to understand chronic illness within the context of travel. Researchers examining affective tourism have noted that much of everyday life endeavours to create order through 'ontological security' for individuals. In creating this sense of order, positivity and emotional security are emphasised, while taboo issues such as death, pain and chronic illness are 'bracketed off'. Despite these attempts at bracketing, travel experiences can prompt individuals to reflect on their own mortality, existence and purpose, which in turn may reshape their travel experiences. For senior travellers, chronic illness may be part of their everyday reality, challenging the individual's sense of self, time and relationships with places, things and people. These topics can be challenging for data collection, because such experiences can be hidden, emotion-laden, difficult to articulate or difficult for others to observe. Researchers have noted the methodological challenges with the use of traditional data tools and have turned to creative visual methods to facilitate and gain deeper understandings of participants' experiences of chronic illnesses. We used one creative visual tool, the 'MeBox' method, to study the hidden aspects of chronic illness and to understand the embodied experience of chronic illness in the context of their travel. The 'MeBox' method was created to understand and communicate the participants' multifaceted experience of chronic illness. The 'MeBox' method contributes to tourism scholarship, particularly for sensitive topics, by facilitating the inclusion of participants' voices to capture their affective travel experiences. This method usefully represents the deeper emotionality of tourists' lived experience that may have otherwise remained invisible to others.
\end{abstract}

Keywords: tourism, chronic illness, hospitality, creative visual research, elderly, MeBox methodology.

\section{Introduction}

Increasingly, tourism scholars have identified the role of emotions and affect in shaping an individual's travel experiences (Bosangit, Hibbert, \& McCabe, 2015; Buda, d'Hauteserre, \& Johnston, 2014; Hosany \& Gilbert, 2010; Martini \& Buda, 2018; McIntosh \& Prentice, 1999). Researchers investigating affective tourism have noted that much of everyday life persists in projecting structure, order and stability in order to create 'ontological security', with death, 
chronic and terminal illness bracketed off or sidelined (Willson, McIntosh, Morgan, \& Sanders, 2018). These topics, still underrepresented in tourism scholarship, present challenges, notably around careful consideration of the method used to ensure the participants' affective experiences are communicated to the researcher (Martini \& Buda, 2018).

As previous scholars (e.g., Chiaranai, Chularee, \& Srithongluang, 2018) have noted, death, pain and illness are intensely shaped by emotions and affect. Yet, this area of consideration is still 'not easily brought into representation' (Martini \& Buda, 2018, p 4) in research, with significant challenges facing researchers, particularly around how to design appropriate methods that communicate the intensity of the participant's emotions and affect. Social networks and others in a person's life, for instance, can often struggle to understand the loss and pain that the person is experiencing. As Main (2014) notes, it becomes 'unshareable because of its resistance to language' (p. 33). Alternative methods are required in order to communicate these emotional and affect experiences. Creative visual methods have been particularly valuable in the health and rehabilitation area as they provide a 'bridge between the conscious and unconscious and therefore [are]helpful for working through complex, deep-seated or 'unspeakable' emotions such as grief' (Reynolds \& Prior, 2003, p. 786). For the researcher, the challenge is how to help participants, who experience pain, grief, loss or illness, to communicate their lived experiences to others in their lives. Deeper consideration then is required around alternative possibilities for methodological tools, especially if the topic has the potential to cause emotional pain that can be deeply felt and long-lasting.

To contribute to this area of tourism scholarship, we draw on a phenomenological study that investigated the travel experiences of senior participants with chronic illness. In this paper, we aim to illustrate the 'MeBox' method and its potential contribution for overcoming the methodological challenges of studying emotion and affect. In the next section, we critically review the literature on the adoption of creative visual methods for understanding difficult to communicate topics. We then provide a detailed explanation of the 'MeBox' method and explain how we applied the tool to our phenomenological study. The latter sections of the paper critically reflect on the use of the method, particularly its use with sensitive participant experiences and/or topics in tourism. People respond differently to chronic illness and it shapes their travel accordingly (Molzahn et al., 2012). When facing crisis situations, each culture has its own ways of reacting and many people are likely to go back to cultural systems based on their beliefs and expectations (Kagawa-Singer, 1998). In this study, we propose the 'MeBox' method as we hope, 
an alternative to traditional methods that can marginalize travellers with chronic illness (Liamputtong, 2007).

\section{Literature Review}

While emotions can be considered as socially constructed, feelings are seen as the body's biological response to something. According to Massumi, emotion is 'a subjective content, the sociolinguistic fixing of the quality of an experience which from that point onward is defined as personal' (Massumi, 2002, p. 28). For Pile (2010), affect is a mood or an atmosphere which is not always perceived clearly and not easily representable. Emotions, feelings and the body are intertwined and, importantly for this study, individuals draw on their body, skin, senses and feelings in order to understand their experiences (Ahmed, 2004; Knights \& Thanem, 2005; Martini \& Buda, 2018; Philipose, 2007). Emotional and affective experiences have been defined as the 'embodied and mindful phenomena that partially shape, and are shaped by our interactions with the people, places and politics that make up our unique, personal geographies' (Davidson \& Bondi, 2004, p. 373).

Living with chronic illnesses such as cardiovascular disease, diabetes, epilepsy, Parkinson's disease, arthritis and many others can lead to difficulties performing familiar tasks and living a 'normal' life (Townsend, Wyke, \& Hunt, 2006). Chronic illnesses are defined as 'those conditions that last a year or more and require ongoing medical attention and/or limit activities of daily living' (Anderson \& Horvath, 2004, p. 263; Chiaranai et al., 2018). Significantly, the symptoms of chronic illness may be mitigated to some extent, but the illness is not curable (Kralik, van Loon, \& Visentin, 2006). Pain and chronic illness is not merely a biological phenomenon but ha[ve] significant social and psychological dimensions' (Tarr \& Thomas, 2011, p. 143). Pain and the trauma of a significant 'disruption' such as long-term chronic illness become 'embodied and become core components of a person's experience of the world' (Philipose, 2007, p. 62). The pain associated with the illness becomes integral to the person's biography, understanding and relationships with others, places and things.

The senior age group differs from other age groups as the majority of seniors are retired, have completed their parental duties and are likely to have the time to reflect deeply about themselves (Jung, 1964). Senior citizens also tend to experience various losses more often than other age groups do (Kim, 2009). Facing a major illness can cause considerable emotional distress, for 
instance, and could lead to the senior individual losing their active social interactions, making them more vulnerable in their communities (Molzahn et al., 2012). Ageing is associated with a greater risk of experiencing long-term chronic illness (Hansson \& Stroebe, 2007). Diabetes, cardiovascular disease and arthritis are among the most common chronic illnesses in elderly people (Chiaranai et al., 2018).

The reasons for the rapid increase in chronic illnesses are due to several factors such as an ageing population with increased life expectancy, as well as improvements in medical technology and lifelong conditions (Anderson \& Horvath, 2004). Chronic illnesses are becoming more prevalent around the world. While many other disciplines are increasingly focused on the growing problem of chronic illnesses among elderly people (Baker \& Wang, 2006; Chiaranai et al., 2018; Palinkas, Wingard, \& Barrett-Connor, 1990), the experiences of people with chronic illness have not received adequate attention in tourism scholarship. Although a growing number of studies within the tourism literature have recently explored the tourism experiences of people with various disabilities (Alén, Domínguez, \& Losada, 2012; Allan, 2015; Kazeminia, Chiappa, \& Jafari, 2015; McIntosh \& Harris, 2018; Tutuncu, 2017; Yau, McKercher, \& Packer, 2004), the voices of elderly people with various chronic illnesses that affect their bodies, affects and emotions remain unheard in tourism scholarship.

Overall, for many seniors with chronic pain and illness, 'the ways in which we understand, experience, perform and talk about emotions are highly related to our sense of body' (Zembylas, 2007, p. 64). In tourism studies, there are currently limited research methods available to deepen our understandings and the meanings of the emotional experiences of people with chronic illnesses. Adopting methods that help individuals encapsulate their understandings and experiences is crucial for both researcher and participant. For the researcher, appropriate methodological tools can help us understand complex emotional issues within the individual's life, understanding, meaning and experiences (Papaloukas, Quincey, \& Williamson, 2017). Taking a participatory and cocreative approach to the research design is essential. For the participant, this approach can facilitate empowerment, feelings of control over the illness and 'wholeness ... [to assist the] process of adjustment and coping with disability and chronic illness' (Rozario, 1997, p. 432).

The majority of tourism management research has focused on traditional tools that emphasize words as the dominant communication mode, obtaining feedback about travel experiences 
through written surveys, in-depth interviews, or focus groups and mystery shoppers (Pullman \& Robson, 2007). These approaches 'have limitations [as they] conform to societal rules and constraints [and] fail to capture the nuances and subtlety of human behaviour' (Westwood, 2007, p. 294). Within health and emotionally sensitive topics, object elicitation can overcome rehearsed 'established narratives' about the individual's condition to elicit critical insightful reflections from being actively involved in the data process (Willig, 2017, p. 213). Affective and emotional experiences are not always expressed in words; thus, they are challenging for researchers to examine. However, the inclusion of nonlinguistic aspects in research allows access to richer, hidden levels of experiences of people living with chronic illnesses (Bagnoli, 2009; Gibbons, 2013).

Visual methods have been widely acknowledged for their therapeutic value in cocreative knowledge production and translation (Fraser \& al Sayah, 2011). Traditional qualitative tourism methods such as interviews rely on language, yet our living experiences involve multiple visual and sensory dimensions, and those experiences cannot always easily be expressed in words (Gibbons, 2013). Indeed, pain is a constantly known sensory experience for those with long-term illness, experience that is not easily translated through written or verbal communication (Philipose, 2007). Creative visual participatory methods are, however, familiar tools in other disciplines such as sociology, health, therapy, rehabilitation, refugee studies, indigenous studies, anthropology and education (Baker \& Wang, 2006; Harrison, 2002; Reynolds, 1997; Rozario, 1997).

Studies that employ creative visual methods aim to achieve meaningful social change outcomes for both researcher and participants (Cockburn-Wootten, McIntosh, Smith, \& Jefferies, 2018). Art, objects and activities have frequently been used during the research process to help scholars gain an understanding of their participants' experiences and, importantly, to help develop the individual's self-esteem to 'resist mastery by her illness' (Reynolds, 1997, p. 355). Refugee and indigenous studies, for instance, use art, objects, creative and participatory methods to overcome difficulties in understanding diverse experiences of trauma and 'othering' and empower participants through involvement and critical reflection to gain control or reframe their lives (Guruge et al., 2015; Lenette \& Boddy, 2013).

Art and objects used within the research process are seen as effective prompts for enabling the tacit emotional and cultural meanings to become explicit. They are used to 'engage participants 
who would otherwise be marginalized or disregarded, and enable[s] reflexivity amongst participants and between the researcher and participants' (Zurba \& Berkes, 2014, p. 822). Furthermore, people in their 60s and above can have great difficulty in remembering and finding words to describe their past experiences (Craik, 1994). In addition, some elderly people can experience fatigue and hearing or visual problems that can impact the interview process (Hall, Longhurst, \& Higginson, 2009). It is, therefore, important to look beyond using traditional methods when exploring the embodied experiences of senior people living and travelling with chronic illnesses.

\section{The 'MeBox' Method in Practice}

This study employed phenomenology and, hence, adopted qualitative research methods to collect data. This approach was chosen due to the distinct strengths of phenomenology in aiding the researcher to interpret the nature of the participants' lived experiences (Willson, McIntosh, \& Zahra, 2013). The phenomenology paradigm, with its primary focus on the individual, body, reflection and lived experiences, offers researchers important opportunities to deepen their understandings of the body, emotions and affect (Knights \& Thanem, 2005). A qualitative approach is appropriate when attempting to draw on inductive indexical understandings and, thus, to better represent the experiences of the participants (Riches \& Dawson, 1996). This perspective has been used effectively by previous scholars to explore the lived experiences of sensitive populations (Lowe, 2005; Richardson \& Balaswamy, 2001).

To achieve this inductive approach, we used the 'MeBox' method to explore the travel experiences of 12 senior citizens. Community communication channels were used to invite potential individuals to participate in the study. For example, information was circulated through acquaintances, community notice boards, not-for-profit organizations such as Age Concern New Zealand, meetup groups, and local churches and interested individuals were invited to contact us directly for more details about the study. The study focused on a sample of research participants aged 65 years and over. The data were collected from New Zealand senior citizens who mainly resided within the North Island region of New Zealand. The recruitment processes helped us to begin the journey towards building a strong rapport with our participants throughout the research process. Before the actual data collection, the first author conducted an initial meeting with participants to clarify expectations around the research process and to discuss confidentiality and ethical aspects of the research. 
The first author conducted the data collection. As he had gained relevant experience through volunteering for various community not-for-profit organisations for elderly people, he ensured that contact information for emotional support services was always available to the participants. The data for this study were collected using the 'MeBox' method as part of an interview process. Gibbons (2010) created this method and used it in a visual anthropology project to understand and communicate the participants' multifaceted experience of chronic illness. The method helped the researcher to study the hidden aspects of chronic illness and to understand the embodied experience of chronic illness (FitzPatrick, Elphingston-Jolly, Friend, \& Payne, 2019). According to Gibbons (2010), 'a 'MeBox' is usually created by gathering together important items that represent different aspects of the person, including hobbies, memories, important milestones, and family history, etc.' (p. 34). In our study the data-gathering locations ranged from the participant's own home to university library rooms to less crowded cafes.

The complexity and multiplicity of lived experiences are not always expressed in words (Bagnoli, 2009; Gibbons, 2013). Therefore, we wanted to include nonlinguistic aspects in our data collection process. The inclusion of the 'MeBox' method within the interview process allowed us to access the hidden levels of the participants' lived emotional experiences. Gibbons used only the 'MeBox' method to collect data in her study (Gibbons, 2010). However, in our study, we employed the 'MeBox' method to complement in-depth interviews with participants. Therefore, we had to adapt the 'MeBox' method into our research process. The standard 'MeBox' method involved three sessions: first, an introductory meeting; second, a session in which participants started to create the 'MeBox'; and third, a final session in which the 'MeBox' was completed from participant-provided objects.

However, in this study, an initial preliminary conversation was held with participants. This was followed by the first in-depth interview and then the second interview, where we employed the 'MeBox' method. These steps are discussed further below. A preliminary conversation enabled the first author to explain the research process and, more specifically, the 'MeBox' method to the participants. This initial conversation informed the participants about all aspects of the study and helped them make their participation decision (Smythe \& Murray, 2000). The first interview was held approximately 2 to 3 weeks after the preliminary conversation, with the participants deciding an interview date, time, and place that was convenient for them. The first author asked the participants directed open-ended questions, in line with Giorgi (1997). The questions were broad and open-ended so that the participants had sufficient opportunity to express their viewpoint extensively. These open-ended questions encouraged participants to discuss different 
aspects of life which then provided a base for the 'MeBox' interview (FitzPatrick et al., 2019). At the end of the first interview, the researcher explained the next stage of the interview process, the 'MeBox' sessions.

The initial stage of creating the 'MeBox' occurred during the second interview. This interview took place approximately 2 to 3 weeks after the first interview. Having time between the first and second interviews gave participants enough time to emotionally prepare for the interview and decide which objects for reflecting on their experiences to select. The participants selected certain objects that were personally important relative to the study (FitzPatrick et al., 2019). At the beginning of the second interview, the first author set out a range of gift boxes so that participants could choose one to be their 'MeBox'. The second interview was conducted in two parts. In the first half, researcher-provided objects were used in the process of completing the 'MeBox'. These artefacts were designed to help the participants to create their 'MeBox' and represent their lived experiences. Initially, the objects provided by the researcher acted as visual stimuli to elicit data (FitzPatrick et al., 2019). The researcher-provided objects eased the participants into the method, as the researcher offered some everyday objects such as a candle, flower, diary, etc. that participants could use to describe their lived experiences (FitzPatrick et al., 2019). In the second half of the interview, the participant completed the 'MeBox' using participant-provided objects.

While the interviewer had his own ideas of what the objects he provided meant, the participants were free to choose or reject any of the objects offered and free also to assign their own meaning to any object they chose. For example, one of the objects the researcher's list offered was a partly burnt candle. For him, this object represented later life and reflections on mortality. However, many participants saw it as the light of God in their life. The interviewer left the room or interview area while the participants chose their 'MeBox' objects. Participants were asked to look at the interviewer-provided objects and pick out any they believed related to their experiences. By leaving the interpretation of the objects relatively open, participants were able to select and add objects to their 'MeBox' that reflected their experiences. The participants were then invited to pick the object that they felt most comfortable talking about first.

The second half of the interview started with the researcher inviting participants to talk about the objects that they had brought and also to add any further missing objects to their 'MeBox' that they felt would reflect their experiences. This interview took approximately 90-120 minutes with each participant. The interview continued until it reached a natural conclusion where information 
was no longer new (Becker, 1992). The 'MeBox' objects facilitated the researcher's exploration of the participant's experiences. The interviewer took photos of the 'MeBox' objects individually and as a group. Photographing 'MeBox' objects allowed the researcher to visually represent the study's findings on the 'MeBox' process and to provide images for the researcher to create hypertextual self-scape images of participants' lived experiences (Elphingston-Jolly, 2012; FitzPatrick, Elphingston-Jolly, Friend, \& Payne; Gibbons, 2010). According to Gibbons (2013), the hypertextual self-scape image has the potential to enable the viewer to gain a level of access to the lived experience (p. 28).

Gibbons' aim in creating this method was to understand and communicate the participant's multifaceted experiences. However, Gibbons (2013) has argued that photographs can miss some sensory information; in her research, participants said they believed that the snapshot put forward a false reality, as their illness is not visible in the photographs. Moreover, Gibbons pointed out that even the $2 \mathrm{D}$ photographs of the objects could miss the multisensory narratives. Therefore, she turned those images into hypertextual self-scape images as a way to add more information that was still missing in the photographs (Gibbons, 2013). In representing these lived emotional experiences, we, therefore, added in art forms to create hypertextual self-scape images (Gibbons, 2013). After creating these images, we sent them to our participants. We asked for their comments and for any changes they wanted in their hypertextual self-scape (Gibbons, 2013). (Gibbons, 2013). According to Gibbons (2013), it is important that participants identify themselves and their lived experiences before hypertextual self-scape images goes public.

\section{Results}

As mentioned previously, a key challenge for participants with a chronic illness is the difficulty in communicating and describing to researchers their lived experiences and how these shape their lives (Main, 2014). Art, music and creative methods can provide a bridge between the body, emotions and social life (Letherby \& Davidson, 2015). The results presented below illustrate how the 'MeBox' objects overcame communication challenges to reflecting on interpretations, connections and relationships of senior participants travelling with a chronic illness. It helped them think with, and through, affects feelings, emotions, a sense of self, and in some cases reconstructed an understanding of the senior participant's life. We have illustrated this process through one of our research participants, Jane. This example provides a rich and insightful understanding not only of how the 'MeBox' method was able to communicate unseen emotional experiences of chronic illness and travel, but also how researchers can use the 'MeBox' method 
to study and analyse emotion/affect (Wood \& Kenyon, 2018). The latter half of this paper provides a critical reflection on the method's contributions to the role of emotion/affect in tourism research. The objects chosen by Jane during the 'MeBox' session represent her lived emotional experiences.

\section{Jane's 'MeBox'}

Jane is a New Zealand senior citizen who had recently faced eye cancer; she describes herself as a 'people person'.

Figure 1: Jane's 'MeBox'

"Source: Authors"

Jane chose the box shown in Figure 1 as her 'MeBox' from the collection of boxes which we provided at the beginning of the interview. This section describes the objects which Jane included in her 'MeBox'.

Figure 2: Bible

"Source: Used with permission"

Jane wanted to put this bible at the centre of her 'MeBox' because the bible represents her travel guide through life. Jane said that after facing eye cancer, her belief in God had become the centre of her life and provided stability. The bible was her go-to book for comfort, strength and assurance during those tough times.

Figure 3: Broken Pot

"Source: Authors"

The broken pot reminded Jane that her life is cracked and she is a broken vessel full of imperfections. For example, she explained:

Life has broken me in places. I lost my eye, so I am not perfect anymore. That grounds me to the reality of who I am, that I am a flawed human being. I said to God, how can I live with one eye? I know people do, but I do not want to be one of those people.

The broken area of the pot reflects her attitude towards life: 'How my broken spots or my rough edges may affect the relationships with other people'. Through this broken pot, she expressed how she felt valued in the tourism context: 
And again, I think of hotel rooms. We are all staying overseas where people have suddenly realized I have not been able to see as well as I could, have opened a door or done some similar seemingly small act of kindness. When I am thumping with my card and trying to get it on the slot on the door and cannot see. It is sort of, it is okay, you're broken, but you're all right. Moreover, I can feel very valued and a very moving moment.

She further explained her emotions before and after getting her prosthetic eye. 'The people, if you do accidentally bump into them or they bump into you, most people are so lovely, and they stop. They are just like, I am sorry. Are you okay?' Moreover, once she got her prosthetic eye, she mentioned that she almost missed feeling special, as she commented that when she had a bandage around her head, it was obvious that something was wrong, so others treated her in the nicest way. In her words, 'And when you get your prosthetic, and you just blend back into humanity, you kind of, I do not feel quite so special anymore. I'm just normal'. In the same way when looking from one angle, we do not see that this pot is broken; it looks complete. Metaphorically, this completeness/incompleteness is the same for Jane, as other people may not initially be able to see her prosthetic eye.

Because of my age, I am not sure what people see first, whether they see my age first - that I am an older lady - or whether they see my prosthetic eye. Moreover, I suspect they see me as an older lady first. Moreover, many people do not know that I am wearing a prosthetic eye. So, I think their reaction to me when I travel is seeing me first as an older woman travelling.

This quote demonstrates how Jane perceives the depth of her inclusion in the travel experience. Further, this example suggests how much more difficult it is to understand the multiplicity of the experiences of those living with chronic illness, notably in the context of travel. The broken pot, for instance, revealed some of Jane's emotional experiences of travel that related to her body. Also, the broken pot shows when Jane's illness became visible to other people and her. At those times, Jane's pain and chronic illness acted as a bridge that connected her with others and sometimes made her feel included, yet on occasions distanced her from others. For Jane, her cancer and its repercussions meant that she needed time to heal and come to terms with her changed identity.

Figure 4: Toy Car

"Source: Authors" 
This toy car reminded Jane of her recent travel experience in Chicago. The noise and vibrancy of the city affected her, probably even more so because she comes from a rural farming background. Jane said she felt that

We are all different. We are all going in our different directions at times, and we're all in a hurry to get there sometimes. And we're focused on often where we're going as an individual. And at times, it can create quite a mayhem, and we can get caught up in it and miss, in the hustle and bustle, we can miss the sacredness, I suppose, of our life's journey. But that does not mean that our life's journey is all peace and quiet. Life is also exciting because it brings changes, it brings challenges, and that is part of living. So that probably balances the quiet retreat side with the energy that comes from living and being amongst others.

\section{Figure 5: Medal \\ "Source: Authors"}

According to Jane, this medal represents running a race for God and the importance of continuing to run, being part of that race, not stopping and falling out. In her words, 'that reminds me I am on a race and to continue faithfully to the end. So, there is a prize, I suppose you'd call it, in the end, and that's what I'm working for'.

The objects chosen by Jane represented a variety of different aspects of her illness and travel experiences. These examples show us that the 'MeBox' method provides researchers with opportunities to represent a participant's experiences in ways that differ from traditional research methods. The 'MeBox' images were able to add the initial layer of emotional experiences of travelling with a chronic illness. The researcher then created a hypertextual self-scape image by digitally altering the images, with the aim of providing more information about the sensory experiences of travelling with a chronic illness (Gibbons, 2010, 2013).

As Gibbons (2013) states:

'through our actions and symbols on the body, we communicate about ourselves beyond what we say... therefore, making hidden illness visible is more than creating pictures and images; it is about recreating the missing information and returning it to the discourse about chronic illness. (p. 19)

The 'MeBox' and hypertextual self-scape image creation enable unseen information and experiences to be represented and communicated to the viewer. These helped the participants to externalize their emotions and chronic illness more fully for the researchers (Gibbons, 2013). Jane's 'MeBox' images illustrate her lived experiences with illness. Through the major loss of 
one eye, Jane's life had taken a social, material and existential turn that forced her on to a new course. Jane believes that if she had not had these experiences, despite their pain and negativity, she would have been a different person, but perhaps not a better person. The 'MeBox' methodology shows that through the use of objects and hypertextual self-scape images, researchers can communicate more information about people's emotions than can be conveyed through words alone (Gibbons, 2013). The images shown above were created using the information gathered during the interview sessions, which included listening to the audio recordings of the interviews, and by looking at the photographs of the 'MeBox' objects and reviewing the sessions (Gibbons, 2013).

Figure 6: Hypertextual self-scape image

"Source: Authors"

The hypertextual self-scape image above represents and brings together Jane's story in a more complex way than the individual items in the 'MeBox' can do. The collated image shows a broken pot, a bible, a toy car, a flower and a medal. The hypertextual self-scape image which shows a broken pot, a bible, a toy car, a flower and a medal brings together three elements from Jane's life experience and, especially, her experience of losing her eye to eye cancer. The pot represents that fact that she saw herself as 'broken and 'imperfect' after her surgery. In her words, 'knowing that coming out of it, I would be even less perfect than what I am. Not that I was perfect before, but even more broken'. The bible represents the comfort she gained from her strengthened belief in God.

In the collated image, the toy car represents Jane's travels after facing cancer. These broadened her perspective on life and kept her in touch with life in all its different forms and shapes. Cancer made Jane reflect, appreciate life and take advantage of exciting experiences whenever they came her way, as she stated, 'If you get the opportunity to travel with your daughter to Adelaide or Chicago, go for it'. Further, travelling with a serious condition made her realize that life is exciting because it brings changes, it brings challenges, and that that is all part of living. Jane's comments suggest that her chronic illness had strengthened her. For example, when she said: 'I think they [her travels] brought out in me qualities that needed to be brought forward to strengthen my faith, to find what I could do as a person'.

Overall, Jane's life is akin to a broken vessel. Depending on which angle you view the pot from, she can be interpreted differently or her illness can be hidden. Overall, however, she confirms that she is still usable and functions. Her broken pot is filled with travel memories, her increased 
belief in God and the belief that she can still flower. In this image, the centre of the flower represents the medal, which Jane says she is winning now. She did not lie down under the experience of having cancer; instead she faced it successfully and won a medal, something which she had never achieved before in her life.

\section{Critical Reflection on the 'MeBox' Method}

The results of the study highlight how participants differentiated the 'Mebox' method from general interviews. During our research, many participants stated that they enjoyed the 'MeBox' process and the opportunity to talk. For example, Jane explained:

I don't mind the direct questions. I sometimes need to stop and think and then go home, driving home think, gosh, did I answer that right, or did I get lost halfway through my answer? Which I could be willing to, but because I am a visual person, I really like having physical objects that I can put out there and talk about. I found that perhaps more helpful than the direct questions. Objects feel more personal to me because I can touch them, hold them and see them. Words for me are good, I like words but visually, I'm much stronger visually.

The introduction of a visual element is, therefore, helpful for the process of idea generation, as it allows participants to move beyond the verbal mode of thinking and to think about wider dimensions of experience (Bagnoli, 2009). All of our participants were over 65 and some had difficulties in remembering their experiences in the initial meeting. For example, Lily said, 'And now I've forgotten, sorry, what the other situation was, there was one other situation. Can I tell you later if I remember?' However, it is interesting to note that, in general, participants did not have difficulty remembering during the 'MeBox' session. For example, as one participant explained:

It helps me to remember the things that I value, the experiences that I have and the joy that they have brought me at the time or the sadness that they have brought me, which is part of, I suppose, the weaving of life.

Further, the meaning of objects was not discussed with the participants in advance, so each was free to assign their own meanings to any object.

Additionally, some participants felt that the 'MeBox' interview experience was therapeutic. Generally, older people agree to participate in research to increase their human contact (Hall, Longhurst, \& Higginson, 2009). Moreover, after an emotional experience, there tends to be a natural desire to share those feelings with others (Wood \& Kenyon, 2018). It is important to note 
that the elderly participants were also able to benefit from participating in this research by having someone to listen to them and to have someone with whom to share their experiences (Hall et al., 2009). Such a research experience can be part of a healing process and can help to develop new understandings of past events. As one participant explained:

I would classify it as therapeutic because I think it's therapeutic in the sense that it's good to remember. And whether those memories are good or bad, I think as time goes on, you can look back and reflect on them and think, it can be therapeutic to do so.

Participants identified that the 'MeBox' process helped them with recognition, provided context, memory cues and allowed one-to-one time to share their experiences. The objects became effective memory prompts for the participants to recall and analyze their experiences. They enjoyed having someone to share their stories about travelling with chronic illness. The visual and tactical nature of the objects provided mindful, in-the-moment reflections for them during the process. The participants were also involved as active meaning makers in the research process rather than passive respondents to researcher questions. Furthermore, this study's results also suggested that this method is ideal for use with small samples, as it requires time and commitment from both participants and researchers.

\section{Discussion}

The participant's experiences suggest how much more difficult it is to understand the multiplicity of experiences of living with chronic illness, notably in the context of travel. Participants with chronic illness and researchers or tourism professionals may hold very different interpretations about the condition, including its limitations and opportunities. The same way found to be true with other studies, for example, Gibbons (2013), which stated that 'when standing in front of a person who has a healthy appearance and is smiling, the symbols of health on the body can trigger the thought that this person is not ill' (Gibbons, 2013, p. 17). In another example from King (2018), a participant stated:

...on most days, I am able to wake up and go to sleep after a normal day - my interactions with those around me have been normal, and everybody has treated and thought of me as 'normal'. For the most part, I have always felt it a benefit to have an invisible illness. (p. 403) 
These examples suggest that in circumstances impacted by long-term pain, ill-health and other physical issues, the body's skin effectively becomes the boundary between what is internally experienced and what is externally seen (Gibbons, 2013).

Therefore, in taking this perspective in the tourism context, this paper has illustrated the potential opportunities of the 'MeBox' method for researchers. The method allows participants to reflect and engage with the process in order to communicate the real emotional and bodily experiences of travelling with chronic illness. It was clear that participants felt their chronic illness often affected relationships with other people, who would see them as a person who lives with a malfunctioning body. Instead, participants described how the travel journey helped them to reconsider their self-identity. This reassessment was illustrated by Jane, as she moved during the 'MeBox' process from seeing herself as 'a flawed human being' to accepting that '[1]ife is also exciting because it brings changes, it brings challenges, and that is part of living'. Similarly, other studies in disciplines such as medicine, for example, have identified that visual and creative methods have helped people with a chronic illness to resist their illness and focus on other things in their lives (King, 2018).

Many people with a chronic illness try to bracket or hide their illness from others, framing it as not a distinguishing feature of their lives (King, 2018). For example, in King's study (2018), one participant with chronic illness stated: 'I spend most of my time focusing on everything else in life, trying to keep any time devoted to my illness away from the eyes of the world' (p. 402). Many research participants endeavour to project and perform as a 'normal' and 'healthy' person. This self-portrayal provides a challenge for service providers in the tourism sector when catering to this segment, due to the imbalance between what is visible externally and the real lived affective experience of chronic illness (Gibbons, 2013). However, the results of our study highlighted that the 'MeBox' method had the potential to capture these hidden aspects of living with chronic illness that participants experience and enable them to reflect on, and share, emotions that are not easy to communicate through words alone (Gibbons, 2013).

In doing so, many participants enjoyed the interview experience and, in comparison to general interviews, participants liked the 'MeBox' research method. For example, Gibbons (2013) pointed out that for a person with chronic illness a simple question such as "“What do you do?" can cause an inside conversation of "What do I tell them?," "Do I really want to start this discussion?" and "Do I have to put my life out there to be judged?"' (p. 18). In these scenarios, traditional talk-based tools would miss this internal reflection and opportunities for critical 
reflection. Instead, a creative and visual technique such as the 'MeBox' method can help researchers and participants elicit deeper understandings and insights that might not be accessible through other data collection methods (Banks, 2007; Pink, Kürti, \& Afonso, 2004; Rakic \& Chambers, 2009). Selecting and touching the objects helped the participants to remember and describe them, notably as skin 'brings to its surface a remembered past' (Prosser, 2001, p. 52). This method helped participants to think in different ways and overcome silences. Indeed, participants in our study stated that the 'MeBox' method gave them the opportunity to revisit the experience and easily express themselves. The researcher-provided objects eased participants into the method and helped them to create their own 'MeBox' to start the data generation process.

The participants' comments emphasise the potential empowerment and therapeutic value of the 'MeBox' research method and its ability for reflection and sharing of experiences that were especially meaningful to them. Research into the potential therapeutic benefits of using similar visual methods in tourism studies remains limited and requires further investigation. For example, researchers can differ in terms of how they approach, conceptualise and respond to the experiences to their participants, especially participants who face chronic illness. There is also the potential for the research to cause emotional pain to participants (Hadjistavropoulos \& Smythe, 2001; Rydzik, Pritchard, Morgan, \& Sedgley, 2012), as there are specific challenges when investigating sensitive topics in tourism, particularly participant experiences that warrant deeper consideration.

When exploring sensitive topics, researchers cannot predict how their data collection will unfold (Hadjistavropoulos \& Smythe, 2001). Therefore, as researchers, we need to reflect on our understandings, strengths and weaknesses. As Bourne and Robson (2015) have stated, researchers 'may need to consider how to handle, or draw boundaries within, interviews where they feel the participant is seeking a degree of therapeutic support they are unable or insufficiently skilled to provide' (p. 114). Tourism researchers need to consider these aspects when studying how individuals with chronic illnesses experience various tourist environments: specifically, how to ethically design research that represents people's experiences in an inclusive and humane way. A perspective that acknowledges humane, affective, emotional and existential lived experience is likely to have a positive impact on people's lives. Therefore, in comparison to the natural sciences research model, the 'MeBox' direction was highly influenced by the research participants in this study. However, the researcher also played a significant role in the 'MeBox' process. For example, the researcher also offered objects for participants to use when 
creating their 'MeBox'. These objects acted as visual stimuli to elicit data and eased the participants into the method.

The 'MeBox' and hypertextual self-scape image added a new layer of narrative by representing the sensory experiences of the participants. When examining participants' experiences, researchers can struggle to understand the embodied understandings of the travel, while participants may be unable to articulate and verbally describe their lived experiences. As Wood and Moss (2015) note when investigating emotional memory and experiences in their work on festivals and events, 'some people have predominantly visual images with no verbal content, others have inner speech with no visual imagery' (p. 48). Creative, visual and object elucidation tools such as the 'MeBox' method overcome this impasse in understanding and the domination of verbal techniques. Further, when using this method, it is important to understand the cultural contexts of the participants. We also think this method is ideal for research that uses small samples, as it requires a significant amount of time and commitment on the part both participants and researchers.

\section{Conclusion}

This paper has illustrated how the 'MeBox' method can function as a tool for examining the emotional experiences of people living with chronic illness in the context of their travel experiences. Chronic long-term illnesses prompt individuals to feel different, judged by others and alienated from their usual surroundings. Emotions and, in particular, bodily sensations such as pain, encourage individuals to reflect, question their existence and reevaluate their relations with others and the environment. For many tourists with chronic illnesses, this process produces feelings of 'inbetweenness' or a liminal space (Buda et al., 2014; Tung \& Brent Ritchie, 2011). The 'MeBox' method offers an effective method for participants, in this case, Jane, to communicate their experiences, reflect on their lives and feel a sense of empowerment over their illness. The meanings of the participants' chronic illness and tourism experiences were different for each individual. For example, the results revealed that some participants experienced feelings

of inclusion and some felt excluded as tourists. However, most of them experienced feelings of insecurity and vulnerability, given their condition. Therefore, tourism researchers could explore the factors that create an unwelcome feeling for people with chronic illness; doing so will lead us to obtain a deeper understanding of this segment's affective behaviour as they seek inclusion and to be viewed as 'normal' in the tourism environment (Baker, Holland, \& KaufmanScarborough, 2007). We also think that people will involve differently in this 'MeBox' process 
in relation to the sensitive topic, and interpretation of the objects based on their culture, gender and age etc. Many tourism researchers are still doubtful about using visual methodologies, mainly because of the general acceptance of conventional methods and the hardships of publishing research outputs which have used visual methods (Rakić \& Chambers, 2010). Other scholars have identified that these tools require time and commitment from both participants and researchers (Rydzik, Pritchard, Morgan, \& Sedgley, 2013). However, our exploratory research shows how this method can be used as a tool, particularly around sensitive topics or where there is a need to involve participants with greater needs to generate sufficient inclusion of participants' voices and capture their affective travel experiences. Furthermore, this method is a very useful way to represent the emotionality of tourists' lived experience that may otherwise remain invisible to others but which is nonetheless significant for understanding the subjective and affective nature of travel.

\section{References}

Ahmed, S. (2004). Collective feelings: Or, the impressions left by others. Theory, Culture \& Society, 21(2), 25-42. doi:10.1177/0263276404042133

Alén, E., Domínguez, T., \& Losada, N. (2012). New opportunities for the tourism market: Senior tourism and accessible tourism. In M. Kasimoğlu (Ed.), Visions for global tourism industry: Creating and sustaining competitive strategies (pp. 139-166). London, England: IntechOpen.

Allan, M. (2015). Accessible tourism in Jordan: Travel constrains and motivations. European Journal of Tourism Research, 10, 109-119.

Anderson, G., \& Horvath, J. (2004). The growing burden of chronic disease in America. Public Health Reports (1974-), 119(3), 263-270.

Bagnoli, A. (2009). Beyond the standard interview: The use of graphic elicitation and arts-based methods. Qualitative Research, 9(5), 547-570. doi:10.1177/1468794109343625

Baker, S. M., Holland, J.,., \& Kaufman.-Scarborough, C. (2007). How consumers with disabilities perceive "welcome" in retail servicescapes: A critical incident study. Journal of Services Marketing, 21(3), 160-173. doi:doi:10.1108/08876040710746525

Baker, T. A., \& Wang, C. C. (2006). Photovoice: Use of a participatory action research method to explore the chronic pain experience in older adults. Qualitative Health Research, 16(10), 14051413. doi:10.1177/1049732306294118

Banks, M. (2007). Using visual data in qualitative research. Retrieved from http://methods.sagepub.com/book/using-visual-data-in-qualitative-research doi:10.4135/9780857020260

Becker, C. S. (1992). Living and relating: An introduction to phenomenology. Newbury Park, CA: Sage Publications.

Bosangit, C., Hibbert, S., \& McCabe, S. (2015). "If I was going to die I should at least be having fun": Travel blogs, meaning and tourist experience. Annals of Tourism Research, 55, 1-14. doi:https://doi.org/10.1016/j.annals.2015.08.001

Bourne, A. H., \& Robson, M. A. (2015). Participants' reflections on being interviewed about risk and sexual behaviour: Implications for collection of qualitative data on sensitive topics. International Journal of Social Research Methodology, 18(1), 105-116. doi:10.1080/13645579.2013.860747 
Buda, D. M., d'Hauteserre, A.-M., \& Johnston, L. (2014). Feeling and tourism studies. Annals of Tourism Research, 46, 102-114. doi:https://doi.org/10.1016/i.annals.2014.03.005

Chiaranai, C., Chularee, S., \& Srithongluang, S. (2018). Older people living with chronic illness. Geriatric Nursing, 39(5), 513-520. doi:https://doi.org/10.1016/j.gerinurse.2018.02.004

Cockburn-Wootten, C., McIntosh, A. J., Smith, K., \& Jefferies, S. (2018). Communicating across tourism silos for inclusive sustainable partnerships. Journal of Sustainable Tourism, 26(9), 1483-1498. doi:10.1080/09669582.2018.1476519

Craik, F. I. M. (1994). Memory changes in normal aging. Current Directions in Psychological Science, 3(5), 155-158.

Davidson, J., \& Bondi, L. I. Z. (2004). Spatialising affect; affecting space: An introduction. Gender, Place \& Culture, 11(3), 373-374. doi:10.1080/0966369042000258686

Elphingston-Jolly, B. L. (2012). Women's use of possessions to cope with abusive relationships. (Unpublished master's dissertation). University of Waikato, Hamilton, New Zealand.

FitzPatrick, M., Elphingston-Jolly, B., Friend, L., \& Payne, P. (2019). Possessions and self in the identity work of survivors of domestic violence. Journal of Consumer Psychology, 29(2), 167-186. doi:10.1002/jcpy.1080

Fraser, K. D., \& al Sayah, F. (2011). Arts-based methods in health research: A systematic review of the literature. Arts \& Health, 3(2), 110-145. doi:10.1080/17533015.2011.561357

Gibbons, R. (2010). A table of metaphors: The visual representation of chronic illness. (Unpublished master's dissertation). Massey University, Albany, New Zealand. Retrieved from http://hdl.handle.net/10179/1520

Gibbons, R. (2013). Hypertextual self-scapes: Crossing the barriers of the skin. In N. K. Denizen (Ed.), 40th anniversary of studies in symbolic interaction (pp. 15-42). Bingley, England: Emerald.

Giorgi, A. (1997). The theory, practice, and evaluation of the phenomenological method as a qualitative research procedure. Journal of Phenomenological Psychology, 28(2), 235-260. doi:https://doi.org/10.1163/156916297X00103

Guruge, S., Hynie, M., Shakya, Y., Akbari, A., Htoo, S., \& Abiyo, S. (2015). Refugee youth and migration: Using arts-informed research to understand changes in their roles and responsibilities. Qualitative Social Research, 16(3) doi:10.17169/fqs-16.3.2278

Hadjistavropoulos, T., \& Smythe, W. E. (2001). Elements of risk in qualitative research. Ethics \& Behavior, 11(2), 163-174. doi:10.1207/S15327019EB1102_4

Hall, S., Longhurst, S., \& Higginson, I. J. (2009). Challenges to conducting research with older people living in nursing homes. BMC Geriatrics, 9, 38-38. doi:10.1186/1471-2318-9-38

Hansson, R. O., \& Stroebe, M. S. (2007). Bereavement in late life: Coping, adaptation, and developmental influences. Washington, DC: American Psychological Association.

Harrison, B. (2002). Seeing health and illness worlds - using visual methodologies in a sociology of health and illness: A methodological review. Sociology of Health \& IIIness, 24(6), 856-872. doi:10.1111/1467-9566.00322

Hosany, S., \& Gilbert, D. (2010). Measuring tourists' emotional experiences toward hedonic holiday destinations. Journal of Travel Research, 49(4), 513-526. doi:10.1177/0047287509349267

Jung, C. G. (1964). Approaching the unconscious. In Man and his symbols (pp. 18-103). New York, NY: Anchor Press.

Kagawa-Singer, M. (1998). The cultural context of death rituals and mourning practices. Oncology Nursing Forum, 25, 1752-1756.

Kazeminia, A., Chiappa, G. D., \& Jafari, J. (2015). Seniors' travel constraints and their coping strategies. Journal of Travel Research, 54(1), 80-93. doi:10.1177/0047287513506290

$\mathrm{Kim}, \mathrm{S}$. H. (2009). The influence of finding meaning and worldview of accepting death on anger among bereaved older spouses. Aging \& Mental Health, 13(1), 38-45. doi:10.1080/13607860802154457

King, J. (2018). Living with a chronic illness. Medicine, 46(7), 402-404. doi:10.1016/j.mpmed.2018.04.007

Knights, D., \& Thanem, T. (2005). Embodying emotional labour. Gender, Bodies and Work, 31-43. 
Kralik, D., van Loon, A., \& Visentin, K. (2006). Resilience in the chronic illness experience. Educational Action Research, 14(2), 187-201. doi:10.1080/09650790600718035

Lenette, C., \& Boddy, J. (2013). Visual ethnography and refugee women: Nuanced understandings of lived experiences. Qualitative Research Journal, 13(1), 72-89.

Letherby, G., \& Davidson, D. (2015). Embodied storytelling: Loss and bereavement, creative practices, and support. Illness, Crisis \& Loss, 23(4), 343-360. doi:10.1177/1054137315590745

Liamputtong, P. (2007). Researching the vulnerable: A guide to sensitive research methods. London, England: Sage.

Lowe, M. E. (2005). The lived experience of untimely spousal bereavement. (Unpublished master's dissertation). University of Saskachewan, Saskatoon, Canada.

Main, S. (2014). Picturing pain: Using creative methods to communicate the experience of chronic pain. Pain News, 12(1), 32-35.

Martini, A., \& Buda, D. M. (2018). Dark tourism and affect: Framing places of death and disaster. Current Issues in Tourism, 1-14.doi:10.1080/13683500.2018.1518972

Massumi, B. (2002). Parables for the virtual: Movement, affect, sensation. Durham, NC: Duke University Press.

McIntosh, A. J., \& Harris, C. (2018). Representations of hospitality at The Special Needs Hotel. International Journal of Hospitality Management, 75, 153-159. doi:https://doi.org/10.1016/j.ijhm.2018.05.021

McIntosh, A. J., \& Prentice, R. C. (1999). Affirming authenticity: Consuming cultural heritage. Annals of Tourism Research, 26(3), 589-612. doi:https://doi.org/10.1016/S0160-7383(99)00010-9

Molzahn, A., Sheilds, L., Bruce, A., Stajduhar, K., Makaroff, K. S., Beuthin, R., et al. (2012). People living with serious illness: Stories of spirituality. Journal of Clinical Nursing, 21(15-16), 2347-2356. doi:10.1111/j.1365-2702.2012.04196.x

Palinkas, L. A., Wingard, D. L., \& Barrett-Connor, E. (1990). Chronic illness and depressive symptoms in the elderly: A population-based study. Journal of Clinical Epidemiology, 43(11), 1131-1141. doi:https://doi.org/10.1016/0895-4356(90)90014-G

Papaloukas, P., Quincey, K., \& Williamson, I. R. (2017). Venturing into the visual voice: Combining photos and interviews in phenomenological inquiry around marginalisation and chronic illness. Qualitative Research in Psychology, 14(4), 415-441. doi:10.1080/14780887.2017.1329364

Philipose, L. (2007). The politics of pain and the end of empire. International Feminist Journal of Politics, 9(1), 60-81. doi:10.1080/14616740601066390

Pile, S. (2010). Emotions and affect in recent human geography. Transactions of the Institute of British Geographers, 35(1), 5-20. doi:10.1111/j.1475-5661.2009.00368.x

Pink, S., Kürti, L., \& Afonso, A. I. (2004). Working images: Visual research and representation in ethnography. London, England: Routledge.

Prosser, J. (2001). Skin memories. In S. Ahmed and J. Stacie (Eds.). Thinking through the skin (pp. 5268). London, England: Routledge.

Pullman, M. E., \& Robson, S. K. A. (2007). Visual methods:Using photographs to capture customers' experience with design. Cornell Hotel and Restaurant Administration Quarterly, 48(2), 121144. doi:10.1177/0010880407300410

Rakic, T., \& Chambers, D. (2009). Researcher with a movie camera: Visual ethnography in the field. Current Issues in Tourism, 12(3), 255-270. doi:10.1080/13683500802401972

Rakić, T., \& Chambers, D. (2010). Innovative techniques in tourism research: An exploration of visual methods and academic filmmaking. International Journal of Tourism Research, 12(4), 379-389. doi:10.1002/jtr.761

Reynolds, F. (1997). Coping with chronic illlness and disability through creative needlecraft. British Journal of Occupational Therapy, 60(8), 352-356. doi:10.1177/030802269706000806

Reynolds, F., \& Prior, S. (2003). 'A lifestyle coat-hanger': A phenomenological study of the meanings of artwork for women coping with chronic illness and disability. Disability and Rehabilitation, 25(14), 785-794. doi:10.1080/0963828031000093486 
Richardson, V. E., \& Balaswamy, S. (2001). Coping with bereavement among elderly widowers. OMEGA - Journal of Death and Dying, 43(2), 129-144. doi:10.2190/y2q6-bb75-enm7-bbyr

Riches, G., \& Dawson, P. (1996). Making stories and taking stories: Methodological reflections on researching grief and marital. British Journal of Guidance \& Counselling, 24(3), 357-365.

Rozario, L. D. (1997). Spirituality in the lives of people with disability and chronic illness: A creative paradigm of wholeness and reconstitution. Disability and Rehabilitation, 19(10), 427-434. doi:10.3109/09638289709166568

Rydzik, A., Pritchard, A., Morgan, N., \& Sedgley, D. (2012). Mobility, migration and hospitality employment: Voices of Central and Eastern European women. Hospitality \& Society, 2(2), 137157. doi:10.1386/hosp.2.2.137_1

Rydzik, A., Pritchard, A., Morgan, N., \& Sedgley, D. (2013). The potential of arts-based transformative research. Annals of Tourism Research, 40, 283-305. doi:https://doi.org/10.1016/j.annals.2012.09.006

Smythe, W. E., \& Murray, M. J. (2000). Owning the story: Ethical considerations in narrative research. Ethics \& Behavior, 10(4), 311-336. doi:10.1207/S15327019EB1004_1

Tarr, J., \& Thomas, H. (2011). Mapping embodiment: Methodologies for representing pain and injury. Qualitative Research, 11(2), 141-157. doi:10.1177/1468794110394067

Townsend, A., Wyke, S., \& Hunt, K. (2006). Self-managing and managing self: Practical and moral dilemmas in accounts of living with chronic illness. Chronic Illness, 2(3), 185-194. doi:10.1177/17423953060020031301

Tung, V., \& Brent Ritchie, J. R. (2011). Exploring the essence of memorable tourism experiences, 38(4), 1367-1386.

Tutuncu, O. (2017). Investigating the accessibility factors affecting hotel satisfaction of people with physical disabilities. International Journal of Hospitality Management, 65, 29-36. doi:https://doi.org/10.1016/j.ijhm.2017.06.002

Westwood, S. (2007). What lies beneath? Using creative, projective and participatory techniques. In I. Ateljevic, A. Pritchard, \& N. Morgan (Eds.), The critical turn in tourism studies: Innovative methodologies (pp. 293-316). Oxford, England, Elsevier

Willig, C. (2017). Reflections on the use of object elicitation. Qualitative Psychology, 4(3), 211-222. doi:10.1037/qup0000054

Willson, G. B., Mclntosh, A. J., Morgan, A., \& Sanders, D. (2018). Terminal illness and tourism: Aa review of current literature and directions for future research. Tourism Recreation Research, 43(2), 268-272. doi:10.1080/02508281.2018.1443053

Willson, G. B., McIntosh, A. J., \& Zahra, A. L. (2013). Tourism and spirituality: A phenomenological analysis. Annals of Tourism Research, 42, 150-168. doi:http://dx.doi.org/10.1016/i.annals.2013.01.016

Wood, E., \& Kenyon, A. J. (2018). Remembering together: The importance of shared emotional memory in event experiences. Event Management, 22(2), 163-181. doi:10.3727/152599518X15173355843325

Wood, E., \& Moss, J. (2015). Capturing emotions: Experience sampling at live music events. Arts and the Market, 5(1), 45-72.

Yau, M. K.-s., McKercher, B., \& Packer, T. L. (2004). Traveling with a disability. Annals of Tourism Research, 31(4), 946-960. doi:http://dx.doi.org/10.1016/i.annals.2004.03.007

Zembylas, M. (2007). Theory and methodology in researching emotions in education. International Journal of Research \& Method in Education, 30(1), 57-72. doi:10.1080/17437270701207785

Zurba, M., \& Berkes, F. (2014). Caring for country through participatory art:Creating a boundary object for communicating Indigenous knowledge and values. Local Environment, 19(8), 821-836. doi:10.1080/13549839.2013.792051 